\section{Development of Social Media Addiction Scale: Validity and reliability study}

\section{Sosyal Medya Bağımlılığ1 Ölçeği (SMBÖ)'nin geliştirilmesi: Geçerlik ve güvenirlik çalışması}

\begin{abstract}
The aim of this study is to develop a scale appropriate for the cultural structure that can be used to measure social media addiction in adolescents. For the scale development process, 67 items were created first and a draft form was obtained following the results of pilot scheme and expert opinions. The validity and reliability studies of the scale were conducted with a total of 830 students, 446 male and 384 female students studying in different secondary schools (7th and 8th grades) and high schools in Amasya during the academic year of 2017-2018. Exploratory factor analysis and confirmatory factor analysis were performed for the validity analysis of the scale. As a result of the exploratory factor analysis, a scale consisting of 24 items and 2 sub-dimensions explaining $51,405 \%$ of the total variance was obtained. Confirmatory factor analysis was performed after that and the fit indices were found to be adequate and the two-factor scale was confirmed $(x 2 / s d=1.89 ; \quad \mathrm{GFI}=.90 ; \quad \mathrm{CFI}=.93$; TLI=.92; RMSEA =.052 and SRMR=0,047).In addition, in order to determine the validity of the scale, its relationship with Bayraktar's (2001) "Internet Dependency Scale" and was evaluated and a significant positive relationship between them was found. The Cronbach Alpha reliability coefficient for the subscales and total of the scale was calculated and found to be sufficient
\end{abstract}

\author{
Nuray Firat ${ }^{1}$ \\ Yaşar Barut $^{2}$
}

Özet

Bu çalışmanın amacı, ergenlerdeki sosyal medya bağımllilğı̆nı ölçmede kullanılabilecek kültürel yapiya uygun bir ölçek geliştirmektir. Ölçek geliştirme sürecinde ilk olarak 67 madde oluşturulmuş, pilot uygulamanın sonuçları ve uzman görüşlerinin ardından taslak bir form elde edilmiş̧iir. Ölçeğin geçerlik ve güvenirlik çalışmalar1 2017-2018 eğitim-öğretim yllında Amasya ilinde farkl ortaokul (7. ve 8. sinif) ve liselerde öğrenim gören 446 erkek ve $384 \mathrm{kız}$ olmak üzere toplam 830 öğrenci katullmılla gerçekleştirilmiştir. Ölçeğin geçerlik analizleri kapsamında açımlayıcı faktör analizi ve doğrulayıcı faktör analizi yapilmışır. Açımlayııı faktör analizi sonucunda toplam varyansın $\% 51,405$ 'ni açiklayan 24 madde ve 2 alt boyuttan oluşan bir ölçek elde edilmiştir. Ardından doğrulayıc faktör analizi yapılmış ve uyum indeksleri yeterli düzeyde bulunarak ölçeğe ilişkin iki faktörlü yap1 doğrulanmıştır $(x 2 / s d=1.89 ; \quad$ GFI $=.90 ; \quad$ CFI $=.93 ; \quad$ TLI=.92; RMSEA $=.052$ ve $S R M R=0,047)$. Ayrrca ölçeğin ölçüt geçerliğini belirlemek amacıyla Bayraktar (2001) tarafindan uyarlanan "İnternet Bağımllilğg Ölçeği” ile arasındaki ilişkiye bakılmış ve aralarında pozitif yönde anlamlı düzeyde ilişki bulunmuştur. Ölçeğin alt boyutları ve toplamına dair Cronbach Alpha güvenirlik katsayısı hesaplanmış ve yeterli düzeyde olduğu (Cronbach $\alpha=.86-.93$ aralı̆ı̆nda) görülmüştür.

\footnotetext{
${ }^{1}$ Ph.D., nry.firat@hotmail.com

2 Dr. Öğr. Üyesi, Ondokuz Mayıs Üniversitesi,Eğitim Fakültesi, Eğitim Bilimleri Bölümü, Rehberlik ve Psikolojik Danışmanlık Anabilim Dalı, Kurupelit/Samsun, ybarut@,omu.edu.tr
} 
Fırat, N., \& Barut, Y. (2018). Sosyal Medya Bağımlllı̆̆ Ölçeği (SMBÖ)'nin geliştirilmesi: Geçerlik ve güvenirlik çalışması. Journal of Human Sciences, 15(4), 2266-2279. doi:10.14687/jhs.v15i4.5181

(Cronbach $\alpha=$ between .86 and .93). In addition to this, to determine the test-retest reliability, the scale was applied to the same group for three weeks and the correlation coefficients were found significant. As a result, the values obtained indicate that Social Media Addiction Scale is a valid and reliable scale to measure social media addiction of adolescents in Turkey.

Keywords: Social media addiction; validity; reliability.

(Extended English summary is at the end of this document)
Bunun yanı sıra test-tekrar test güvenirliğini belirlemek amaciyla ölçek üç hafta arayla aynı gruba uygulanmış ve korelasyon katsayıları anlamlı bulunmuştur. Sonuç olarak, elde edilen değerler Sosyal Medya Bağımlılı̆̆ı Ölçeği’nin Türkiye'deki ergenlerin sosyal medya bağımlılıklarını ölçmede kullanılabilecek geçerli ve güvenilir bir ölçek olduğunu göstermektedir.

\section{Giriş}

Günümüzde, iletişim araçlarının gelişim hızının yanı sıra çeşitliliği de artmıştır. Bu durum etkileşimi kolaylaştırmakta ve internetin kullanım alanının genişlemesine sebep olmaktadır. İletişim aracı olarak birçok teknoloji kullanılmakta fakat yapılan araştırmalar en çok internetin kullanıldığını göstermektedir. İnternet, eğitimden sağlığa, bilimsel çalışmalardan eğlenceye kadar birçok alanda kendisine yer bulmuş (Kenanoğlu ve Kahyaoğlu, 2011) bunun neticesinde de gündelik yaşamda birçok yeniliğe ve değişime sebep olmuştur.

Türkiye İstatistik Kurumu (TUIK) tarafindan 2015 yll Nisan ayında gerçekleştirilen Hanehalkı Bilişim Teknolojileri Kullanım Araştırması sonuçlarına göre mobil telefona sahip olma oranı \%96,8 iken, mobil telefonlardan internete bağlanma oranı ise \%64,7'dir. Yine aynı araştırmanın sonuçları, interneti kullanan bireylerin \%80.9 oranla sosyal medya ve $\% 70.2$ oranla online haber ve gazete siteleri takip etmek amaçlı interneti kullandığını ortaya koymuştur (Türkiye İstatistik Kurumu, 2015). Bu açıdan bakıldığında kullanıcıların internette geçirdikleri zamanın büyük bir kısmını sosyal ağlarda, online haber sitelerinde, film ve müzik sayfalarında geçirmektedir. Dolayısıyla iletişimin en önemli araçlarından biri haline gelen internetin daha çok sosyal amaçlı kullanıldığı görülmektedir.

Web 1.0 teknolojilerinde içeriğin sadece kullanıcı tarafindan okunabildiği yani tek yönlü iletişimin sadece mümkün olduğu bir ortam iken, Web 2.0 teknolojileri ile iletişim çift yönlü olarak gerçekleşmeye başlamışır (D’Souza, 2006). İnsanlar arası iletişimi sağlayan internet, Web 2.0 araçlarının gelişimi ile iletişimin yeni bir boyut kazanmasına olanak sağlamıştır. Sosyal iletişimi yani karşllklı etkileşimi amaç edinen Web 2.0 teknolojilerinin gelişimi ile insanlar günümüzde yeni internet ortamları arayışına girmiştir (Argın, 2013). Bu sayede kullanıcıların da iletişime dâhil olduğu bir yapı oluşturulmaya başlanmıştır (Köseoğlu, 2012). Bu gelişmeler sosyal medya adında yeni platformların oluşmasını sağlamış ve interneti kullanan bireylerin zamanlarını da daha çok sosyal medyada geçirmelerine yol açmışır.

Bireylerin sosyal medya kullanımını artıran teknolojik gelişmelerden biri de akıllı telefonların kullanımıdır. Bir bilgisayar ile yapılabilecek tüm işlemlerin mobil telefon ile de gerçekleştirilebilmesi için tasarlanan akıllı telefonlar, dünyada geniş kitleler tarafindan kullanmaktadır. Uluslararası İstatistik Kurumu (International Data Corporation, IDC)'nun yaptuğı bir araştırmaya göre, 2012 yılında toplam akıllı telefon satıssı 660 milyon adet olarak belirlenmiş ve bu rakamın yıllar geçtikçe artması öngörülmektedir. Akıllı telefonlardaki internet özelliğiyle beraber sosyal medyanın daha kolay ve ucuz erişilir olması, zaman ve mekan sınırlamasının olmaması kullanımının artmasına da olanak sağlamaktadır. 
Fırat, N., \& Barut, Y. (2018). Sosyal Medya Bağımlılığı Ölçeği (SMBÖ)'nin geliștirilmesi: Geçerlik ve güvenirlik çalıșması. Journal of Human Sciences, 15(4), 2266-2279. doi:10.14687/jhs.v15i4.5181

19901 yıllardan itibaren internet bağımlılığı konusu araştırmacıların ilgilisini çekmeye başlamış ve bu konuda hem dünyada hem ülkemizde oldukça fazla çalışma yapılmıştır (Young, 1998; Bayraktar, 2001; Şahin, 2011). Fakat son yirmi yıldır internet tabanlı teknolojik gelişmeler ile birlikte araştırmalar cep telefonu bağımlılığı (Firat ve Balc1, 2017), akıllı telefon bağımlllğı (Şar, Ayas ve Horzum, 2015), sosyal medya bağımllı̆̆1 gibi konularda yoğunlaşmıştur. Ayrıca internet bağımlılığının bir uzantısı şeklinde değerlendirilen sosyal medya kullanımının gün geçtikçe artması ve hatta gündelik yaşamın bir parçası olarak alışkanlık haline gelmesi, araştırmacıların, sosyal medya kullanımını gündeme taşımalarına neden olmuştur (Tutgun-Ünal, 2015). Bu sebeple sosyal medya bağımlılı̆̆ı da araştırmacıların ilgi alanına girmiştir.

Onat (2010) ve Bayram (2012) sosyal medyay1, bireylerin web 2.0 teknolojisini kullanarak, çift yönlü ve birebir iletişime olanak tanıyan, bilgi iletimi ve bunun yanı sıra video, fotoğraf vb. her türlü paylaşımın yapılabildiği yeni bir iletişim kanalı olarak tanımlamışlardır. Çeşitli sosyal medya platformlanı kullanıcıların $\mathrm{O}$ an nerde olduklarını, neler yaptkklarını sunabilmelerine, çektikleri fotoğraf ve videolarını paylaşabilmelerine, sakladıkları düşüncelerini belirtebilmelerine imkan verebilmektedir. Sosyal içerikli sayfaların sunduğu imkanların bu çeşitliliği çocuklardan yetişkinlere kadar her kesimin ilgisini çekmektedir. Günümüzde yapılan araştırmalar özellikle gençlerin daha çok sosyal medyayı kullandıklarını göstermektedir (Akyazı ve Tutgun-Ünal, 2013; Köroğlu ve TutgunÜnal, 2013; Usluel ve Mazman, 2009; Vural ve Bat, 2010). Dolayisyyla Türkiye'de genelde internet kullanımın ve özelde ise sosyal medya kullanımının her geçen gün ergenler arasında yaygın bir biçimde kullanılmasına bağlı olarak ortaya çıkabilecek sorun alanlarının incelenmesi ve takip edilmesi önem taşımaktadır. Ayrıca öğrennim çağında olan ergenlerin aşırı sosyal medya kullanmaları beraberinde kişisel, sosyal, eğitsel ve mesleki alanlarda sorun yaşamalarnna neden olabilmektedir. Bundan dolayı sosyal medya bağımlılı̆̆ını belirleyip önlemler alabilmek için geçerli ve güvenilir ölçeğe ihtiyaç duyulmkatadır.

Alanyazına bakıldığında, sosyal medya bağımlılı̆̆ını belirlemek için ölçme araçlarının geliştirildiği görülmektedir (Al-Menayes, 2015). Yurtiçi alanyazın incelendiğinde daha çok internet bağımlılı̆̆1 üzerine çalışmalar yapıldığı (Günlü, 2016), sosyal medya bağımlılığ1 üzerine yapılan araşturmaların ise yetişkinler ve üniversite öğrencileri ile gerçekleştirildiği (Şahin ve Yağc1, 2017; Tutgun-Ünal, 2015) görülmektedir. Ergenlerden oluşan çalışma grubuyla ise sosyal medyaya ilişkin tutumlar konusunda araştırmalar yapilmıştır (Kılıç, 2016; Otrar ve Argin, 2015). Bu nedenle bu çalışmada ortaokul ve lisede öğrenim gören ergenlerin sosyal medya bağımllıklarını ölçmede kullanılabilecek "Sosyal Medya Bağımlıllğı Ölçeği" geliştirilmiş ve bu süreçte elde edilen bulgulara yer verilmiştir.

\section{Yöntem}

\section{Araştırma Grubu}

Çalışmanın araştırma grubunu 2017-2018 eğitim-öğretim yllında Amasya ilinde bulunan farklı ortaokul (7. ve 8. sınıf) ve liselerde öğrenim görmekte olan öğrenciler oluşturmaktadır. Araştırmanın geçerlik çalışması kapsamında açımlayıcı faktör analizi 320, doğrulayıcı faktör analizi 335, ölçüt geçerliği analizi 125 öğrenci ve güvenirlik çalışması kapsamında test-tekrar test güvenirliğini belirlemek amacıyla yapılan Pearson Çarpım Moment korelasyon analizi 50 öğrenci olmak üzere toplam 830 öğrenci ile gerçekleştirilmiştir. Ayrıca ilkinde 70 ve ikincisinde 72 olmak üzere toplam 142 öğrenci ile iki pilot uygulama gerçekleştirilerek ölçek formu oluşturulmuştur. Araştırmaya katılan öğrencilerin \%46.3’ü kız ve \%53.7'si erkektir.

\section{Veri Toplama Araçları}

$\mathrm{Bu}$ araştırmada veri toplama aracı olarak öğrencilerin cinsiyet ve sınıf düzeyi bilgisinin yer aldığı Kişisel Bilgi Formu ile Sosyal Medya Bağımlılı̆̆ı Ölçeği kullanılmıştır. Ayrıca Sosyal Medya Bağımlılı̆̆ Ölçeği’nin ölçüt geçerliğini belirlemek amacıyla Bayraktar (2001) tarafindan Türkçe'ye uyarlanan İnternet Bağımlılı̆̆ Ölçeği kullanılmıştır. Aşağıda veri toplama araçlarına ilişkin bilgiler sunulduktan sonra bu araştırmada ergenlerin sosyal medya bağımlılı̆̆ını ölçmek amacıyla geliştirilen SMBÖ’nün geçerlik ve güvenirlik çalısmaları sunulmuştur. 
Fırat, N., \& Barut, Y. (2018). Sosyal Medya Bağımlılığı Ölçeği (SMBÖ)'nin geliștirilmesi: Geçerlik ve güvenirlik çalıșması. Journal of Human Sciences, 15(4), 2266-2279. doi:10.14687/jhs.v15i4.5181

\section{İşlem}

Ölçek geliştirme çalışmasında ilk olarak alanyazın ayıntılı biçimde taranmıştır. Sosyal medya ile ilgili yurt içi ve yurt dışındaki çalışmalar ve bu çalışmalarda kullanılan veri toplama araçları incelenmiştir.Konu ayrıntllı biçimde incelendikten sonra 35 kişilik öğrenci grubuna sosyal medya ile ilgili hazırlanan açık uçlu sorular yöneltilerek birer kompozisyon yazdırılmıştır. Daha sonra bu kompozisyonlarda öğrencilerin konu ile ilgili yazmış olduğu ifadeler sistematik bir biçimde değerlendirilmiş ve konu ile ilgili ayırt edici unsurlar, belirtiler veya işaretler belirlenmiştir. Hem alanyazın hem yazılan kompozisyonlar dikkate alınarak sosyal medya bağımlılı̆̆ını ölçebileceği düşünülen 67 maddeden oluşan taslak form hazırlanmıştır. Oluşturulan bu form alanda uzman 5 kişi tarafindan incelenmiştir. Uzmanların görüssleri doğrultusunda gerekli maddeler üzerinde düzeltilerek yeniden yazılmıştır.

Genel uygulama öncesinde gözden kaçmış olası anlatım veya imla hatalarını tespit edip düzeltebilmek ve ölçek formuna ilk şeklini verebilmek için hedef kitle ile benzer özellikler taşıyan 70 kişilik bir öğrenci grubuyla pilot uygulama gerçekleştirilmiştir. Madde seçiminin ilk aşaması olarak yapılan ilk pilot uygulamada güvenirlik analizi sonucunda Cronbach Alpha değeri .97 olarak bulunmuştur. Psikometrik özellik bakımından maddelerin uygun veya problemli olup olmadığını belirlemek için madde analizleri yapılmıştır. Analiz sonucunda madde toplam korelasyon değerlerinin .20'nin üzerinde olduğu görülmüştür. Ayrıca uygulama esnasında öğrencilerden gelen soru ve geri bildirimler dikkate alınarak ölçek formu üzerinde madde ifadeleri üzerinde tekrar düzeltmeler yapılmıştır. Pilot uygulamanın ardından tekrar uzman görüşleri alınarak ölçeğin düzeltmeleri yapılmıss ve ölçek geliştirme sürecinde geçerlik ve güvenirlik analizilerine geçilmiştir.

\section{Bulgular}

\section{Geçerlik ve Güvenirlik Çalışmaları}

SMBÖ'nün geçerlik çalışmaları kapsamında ölçeğin yapı geçerliği ve ölçüt (uyum) geçerliğine ilişkin kanıtlar incelenmiştir. Ölçeğin yap geçerliğine ilişkin ilk olarak açımlayıcı faktör analizi ardından farklı bir veri seti ile doğrulayıcı faktör analizi yapılmıştır. Ölçeğin ölçüt (uyum) geçerliği ise benzer çalışma grubuna sahip İnternet Bağımlılığı Ölçeği (Bayraktar, 2001) ile birlikte test edilmiştir.

\section{Açımlayıcı Faktör Analizi (AFA)}

SMBÖ'nün açımlayıcı faktör analizi (AFA) için Amasya ilinde bulunan farklı ortaokul ve liselerde öğrenim görmekte olan toplam 320 öğrenciden elde edilen veriler kullanılmıştır.Araştırma grubunu oluşturan 320 öğrencinin 174'ü kı (\%54.4), 146's1 erkek (\%45.6)'tir. Verilerin, faktör analizi için uygun olup olmadığı Kaiser-Meyer-Olkin (KMO) katsayısı ve Barlett Sphericity testi ile incelenmiş ve sonuçlar aşağıdaki tabloda sunulmuştur:

Tablo1: KMO and Bartlett's Testi Değerleri

\begin{tabular}{llc}
\hline Kaiser-Meyer-Olkin Örneklem Yeterliliği & & .956 \\
\hline \multirow{3}{*}{ Bartlett's Test of Sphericity } & Ki-kare Değeri & 5100,496 \\
& S.Derecesi & 378 \\
& $P$ & .000 \\
\hline
\end{tabular}

KMO testi, çalışma grubunun faktör analizi için yeterli olup olmadığını test etmektedir. Kaiser bulunan değerin 1'e yaklaştıkça mükemmel, 0.50'nin altında ise kabul edilemez (0.90’larda mükemmel, 0.80'lerde çok iyi, 0.70'lerde ve 0.60'larda vasat, 0.50'lerde kötü) olduğunu belirtmektedir (Tavşanc1l, 2010). Büyüköztürk (2004)'e göre ise verilerin faktör analizine uygunluğu için KMO .60'dan yüksek ve Barlett testinin de anlamlı çıkması gerekmektedir. Temel Bileşenler Analizinde KMO değeri Tablo1'de görüldüğü gibi 96 bulunmuştur. Buna göre bu ölçeğin KMO değeri de "mükemmel" aralığı içinde yer almaktadır. Barlett Küresellik Testi değerinin de anlamlı olduğu $\left[\chi^{2}=5100,496 ; p<0.01\right]$ belirlenmiştir. Bu bulgular doğrultusunda, çalışma grubunun yeterli 
Fırat, N., \& Barut, Y. (2018). Sosyal Medya Bağımlılı̆̆1 Ölçeği (SMBÖ)'nin geliştirilmesi: Geçerlik ve güvenirlik çalışması. Journal of Human Sciences, 15(4), 2266-2279. doi:10.14687/jhs.v15i4.5181

büyüklükte AFA için uygun olduğu saptanmış ve SMBÖ’nün yap1 geçerliğini test etmek için 65 maddelik ölçek formu ile AFA analizine geçilmiştir.

AFA yaparken faktör yük değeri alt limiti olarak .32 alınmış ayrıca aynı maddenin farklı faktörlerdeki yük değerleri arasındaki farkın en az .10 olmasına dikkat edilmiştir. Faktör sayısının belirlenmesinde ise her bir faktörün öz değerinin (eigen) \%1 ve üzeri değer olması esas alınmıştur. Ayrıca her bir alt faktörün ölçekte yer alan toplam varyansın en az \%5'ini açıklaması beklenmektedir (Seçer, 2015). Yapılan ilk faktör analizinde, faktör sayısına herhangi bir sınır getirilmemiş ve öz değeri 1.00 den büyük dört faktör belirlenmiştir. Oluşan bu dört faktör ölçeğin toplam varyansın \%49.9'unu açıklamaktadır. Fakat bu alt faktörlerden dördünün öz değerleri \%1 üzerinde yer aldığ1 ve sadece ikisinin toplam varyansın en az \% $\%$ ’ini açıkladığı belirlenmiştir. Aynı zamanda öz değerlere ilişkin yamaç-birikinti grafiği incelenmiş ve ikinci faktörden sonra ciddi bir düşüşün olduğu ve faktörlerin varyans oranlarının birbirine oldukça yakın olduğu görülmüştür. Bu işlemin ardından Varimax Dik Döndürme Tekniği kullanılarak maddelerin faktörlere dağılımına bakılmış ve bazı maddelerin birden fazla faktörde yüksek değer $(<.30)$ verdiği görülmüştür. Birden fazla faktörden 0.30'dan fazla yük alan maddelerde, yük farkının miktarına bakılmış, bu farkın \%10'dan daha düşük olduğu maddeler ölçekten çıkarılmıştr (Büyüköztürk, 2012). Kalan 28 madde (Madde 1, 3, 5, 6, 7, 8, $9,10,13,16,17,18,19,21,22,25,28,33,34,35,38,40,41,42,43,59,61,65)$ üzerinden sahip olduğu öz değer ve açıkladığı toplam varyans oranından dolayı faktör sayısı iki ile sınırlandırılarak faktör analizi tekrar gerçekleştirilmiştir.

İşlemlere başlamadan önce tekrar KMO katsayısı ve Barlett Sphericity testi yapılmıştur. KMO değeri (.96) ve Bartlett's değerlerinin anlamlllı̆̆ $(p<.001)$ yine çalısma grubunun büyüklügünün ve elde edilen verilerin seçilen analiz için uygun ve yeterli olduğunu göstermektedir. Ardından tekrarlanan analiz sonuçları tabloda sunulmuştur:

Tablo 2: Açıklanan Toplam Varyans Miktarları

\begin{tabular}{|c|c|c|c|c|c|c|}
\hline Faktörler & $\begin{array}{r}\text { Başlan } \\
\text { (Initial }\end{array}$ & $\begin{array}{l}\text { giç Öz D } \\
\text { Eigenval }\end{array}$ & $\begin{array}{l}\text { eğerler } \\
\text { ues) }\end{array}$ & Toplam & Faktör Yükleri & $\begin{array}{l}\text { Faktör Yüklerinin Döndürülmüş } \\
\text { Toplamları }\end{array}$ \\
\hline & Top. & Varyans\% & Küm.\% & Top. & Varyans\% Küm.\% & Top. Varyans\% Küm.\% \\
\hline 1 & 12,545 & 44,805 & 44,805 & 12,545 & $44,805 \quad 44,805$ & $8,0342 \quad 8,6932 \quad 8,693$ \\
\hline 2 & 1,848 & 6,599 & 51,405 & 1,848 & $6,599 \quad 51,405$ & $6,359 \quad 22,711 \quad 51,405$ \\
\hline 28 & .210 & $\begin{array}{ll}\cdots & \\
7449 & 10\end{array}$ & 0.000 & & & \\
\hline
\end{tabular}

Şekil 1: SMBÖ’deki Maddelere Iilişkin Yığılma Grafiği

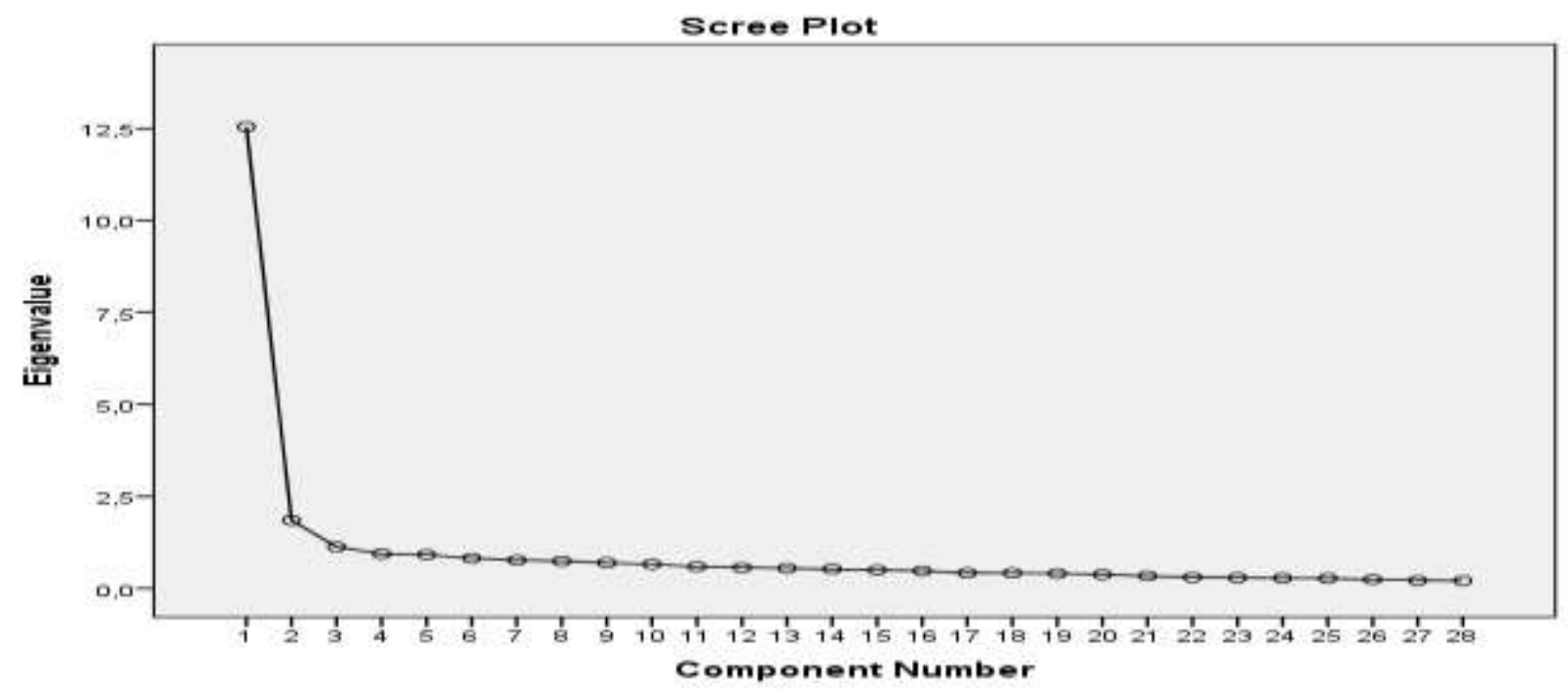


Tablo 2 ve Şekil 1'de görüldüğü gibi öz değeri 1 olarak alındığında ve tekrarlanan faktör analizi sonucunda iki faktör belirlenmektedir. Oluşan iki faktörün öz değerleri birinci faktör için $\% 12.545$, ikinci faktör için \%1.848'dir. Faktörlerin açıkladıkları varyans oranlarınına bakıldığında; birinci faktörün açıkladı̆̆ı varyans oranının \%44,805; ikinci faktörün açıkladığı varyans oranının $\%$ 6,600 olduğu görülmektedir. Açıklanan toplam varyans oranı ise \%51.405 olarak bulunmuştur. Faktör analizi sonunda elde edilen varyans oranlarının yüksekliği ölçeğin faktör yapısının güçlülüğüne işaret etmektedir. Fakat sosyal bilimlerde çok yüksek varyans oranlarına ulaşmak mümkün olmamaktadır. Varyans oranlarında \%40 ile \%60 arasında değişen değerler yeterli olarak kabul edilmektedir (Tavşancıl, 2010). Maddelerin faktörlere dağılımını belirlemek için yapılan Varimax dik döndürme analizi yapılmış ve sonuçları ise aşağıdaki tabloda sunulmuştur:

Tablo 3: Faktör Analizi Sonrası Dönüştürülmüş Bileşenler Matriksi

\begin{tabular}{lcc}
\hline & & Faktörler \\
\hline Maddeler & 1 & 2 \\
\hline Madde58 & .767 & \\
Madde64 & .745 & \\
Madde56 & .742 & \\
Madde30 & .722 & \\
Madde44 & .719 & \\
Madde47 & .683 & \\
Madde55 & .665 & \\
Madde24 & .664 & \\
Madde23 & .634 & \\
Madde51 & .620 & \\
Madde31 & .614 & \\
Madde15 & .607 & \\
Madde14 & .604 & \\
Madde2 & .552 & \\
Madde63 & .511 & \\
Madde50 & .509 & \\
Madde48 & .483 & .765 \\
Madde53 & & .724 \\
Madde62 & & .606 \\
Madde54 & & .693 \\
Madde52 & & .638 \\
Madde60 & & \\
Madde45 & & \\
Madde27 & & \\
Madde49 & & \\
Madde20 & & \\
Madde46 & & \\
Madde32 & & \\
\hline
\end{tabular}

Tablo 3’te görüldüğü gibi Varimax Dik Döndürme Tekniği kullanılarak yapılan analiz sonucunda maddelerin faktörlere dağılımına bakıldığında ölçeğin öz değeri 1'den büyük 2 faktörde toplandığı, tüm maddelerin girdikleri faktörde kabul edilebilir yük değerlerine sahip (en düşük madde yük değerinin 0.483; en yüksek madde yük değerinin 0.767 ) olduğu görülmüştür. Birden fazla faktörde yüksek değer veren maddeler arasında ise en az .10 değerinin bulunmasina dikkat edilmiştir. Faktörler altında toplanan maddeler ve madde sayılarını gösteren tablo aşağıda sunulmuştur: 
Fırat, N., \& Barut, Y. (2018). Sosyal Medya Bağımlılı̆̆1 Ölçeği (SMBÖ)'nin geliştirilmesi: Geçerlik ve güvenirlik çalışması. Journal of Human Sciences, 15(4), 2266-2279. doi:10.14687/jhs.v15i4.5181

Tablo 4: Faktör Analizi Sonucunda Belirlenen Alt Boyutlar ve Bu Boyutlardan Yük Alan Maddeler

\begin{tabular}{ccc}
\hline Faktör & Madde Say1s1 & Madde Numaras1 \\
\hline 1 & 17 & $58,64,56,30,44,47,55,24,23,51$, \\
& & $31,15,14,2,63,50,48$ \\
2 & 11 & $4,7,10,12,13,16,19,20,21,25,26$ \\
\hline
\end{tabular}

Tablo 4'te görüldüğg̈ü üzere ölçek 28 madde ve 2 faktörden oluşmaktadır. Birinci faktör 17 maddeden $(58,64,56,30,44,47,55,24,23,51,31,15,14,2,63,50,48$. maddeler), ikinci faktör 11 maddeden $(4,7,10,12,13,16,19,20,21,25,26$. maddeler) oluşmaktadır. Her bir faktör içine giren maddeler incelenerek oluşan alt boyutlar isimlendirilmiştir. Bu bağlamda birinci alt boyut "Yoksunluk" alt boyutu olarak; ikinci alt boyut "Günlük Yaşamı Etkileme/Kontrolsüzlük" alt boyutu olarak isimlendirilmesi uygun görülmüştür.

\section{Güvenirlik Analizi}

Faktörlerin tespiti ve isimlendirilmesi işleminin ardından, faktörler arasında anlamlı bir ilişki bulunup bulunmadığını belirlemek amacıyla yapılan Pearson Çarpım Moment Korelasyon analizi gerçekleştirilmiştir. Sonuçlar aşağıda sunulmuştur:

Tablo 5: Faktörler Arası İlişkileri Belirlemek İçin Yapılan Pearson Çarpım Moment Korelasyon Analizi Sonuçları

\begin{tabular}{lccc}
\hline Alt Boyutlar & Yoksunluk & GünlükYaşamı Etkileme/Kontrolsüzlük & Toplam \\
\hline Yoksunluk & 1.00 & .677 & .962 \\
Günlük Yaşamı Etkileme & & 1.00 & .853 \\
Toplam & & & 1.00 \\
\hline
\end{tabular}

Ölçekte belirlenen faktörler arasında anlamlı bir ilişki bulunup bulunmadığını belirlemek amacıyla yapılan Pearson Çarpım Moment Korelasyon analizi sonucunda faktörler arasında pozitif yönde anlamlı bir ilişki olduğu belirlenmiştir. Yoksunluk alt boyutu ile Günlük Yaşamı Etkileme/Kontrolsüzlük alt boyutu arasında $(r=.677 ; p<.001)$ pozitif yönde anlamlı bir ilişki olduğu görülmüsşür. Elde edilen bu değerler faktörlerin aynı yapı içinde olduklarını ortaya koymaktadır.

Güvenirlik analizi kapsamında ölçeğin alt boyutları ve toplamına dair iç tutarlık güvenirliği Cronbach Alfa katsayısı $(\alpha)$ ile hesaplanmıştur. Yapılan analiz sonucunda, Cronbach alpha değerleri yoksunluk alt boyutu için .90 , günlük yaşamı etkileme/kontrolsüzlük alt boyutu için .86 ve son olarak ölçeğin toplamı için .93 olarak elde edilmiştir. Bir veri toplama aracının güvenilirlik katsayısının .70 veya daha üzerinde olması, güvenilirlik için yeterli bir değer olarak belirtilmektedir (Büyüköztürk, 2010). Elde edilen bu değerler, ölçeğin iç tutarlılığının yüksek olduğunu ortaya koymaktadır.

\section{Doğrulayıc1 Faktör Analizi (DFA)}

SMBÖ’nün yapı geçerliğini incelemek amacıyla bu iki faktörlü yapı üzerinde Amos programı kullanılarak doğrulayıcı faktör analizi (DFA) yapılmıştır. DFA, Amasya ilinde farklı ortaokul ve liselerde öğrenim görmekte olan toplam 335 öğrenciden elde edilen farklı bir veri seti üzerinde gerçekleştirilmiştir.Çalışma grubunu oluşturan 335 öğrencinin 143’ü kız (\%42.7), 192'si erkek (\%57.3)'tir. Model tanımlamasında maddelerin iki faktör ile temsil edileceği ve 17 maddenin "Yoksunluk" ve 11 maddenin "Günlük Yaşamı Etkileme/Kontrolsüzlük" faktörlerinde yer alacağ1 hipotezi sınanmıştur. DFA sonucunda $x 2 / s d$ oranının $(x 2 / s d=2.320) 5$ 'ten küçük olduğu ve yeterli uyuma işaret ettiği görülmektedir. Ancak, diğer uyum iyiliği indeksleri incelendiğinde modelin uyumunun iyi olmadığı görülmektedir (GFI=.85, AGFI=.82, CFI=.88, RMSEA= .063). Bundan dolayı analiz sonucunda elde edilen değişiklik önerileri (modification indices) incelendiğinde, madde 27'nin faktör yükünün düşük olduğu, madde 18 ile madde 9'un her iki boyuta düştüğü, madde 23 'ün ise her iki boyutta da faktör yükünün yüksek olduğu görülmüş ve ölçekten çıkarılmışlardır. 
Fırat, N., \& Barut, Y. (2018). Sosyal Medya Bağımlılı̆̆1 Ölçeği (SMBÖ)'nin geliştirilmesi: Geçerlik ve güvenirlik çalışması. Journal of Human Sciences, 15(4), 2266-2279. doi:10.14687/jhs.v15i4.5181

Ayrıca madde 4 ve madde 6 ile madde 21 ve madde 26'ya ait hatalar arasında ilişki olduğu anlaşılmıştur. Bu maddelere ilişkin hata kovaryansları ilişkilendirilerek analiz tekrarlanmışır (Byrne, 2010). Tekrarlanan doğrulayıcı faktör analizi sonucunda elde edilen uyum indeksi değerleri ile modele ilişkin path diagramı ve faktör yükleri aşağıda sunulmuştur:

Tablo5: SMBÖ’nün Doğrulayıc1 Faktör Analizi Sonuçları

\begin{tabular}{lcccccccc} 
& $\chi^{2}$ & sd & $\chi^{2} /$ sd & GFI & CFI & TLI & RMSEA & SMRM \\
\hline İstatistikler & 469.858 & 249 & 1.89 & .90 & .93 & .92 & .94 & .047
\end{tabular}

Not: sd: Serbestlik Derecesi.

Şekil 2: SMBÖ Path Diagramı ve Faktör Yükleri

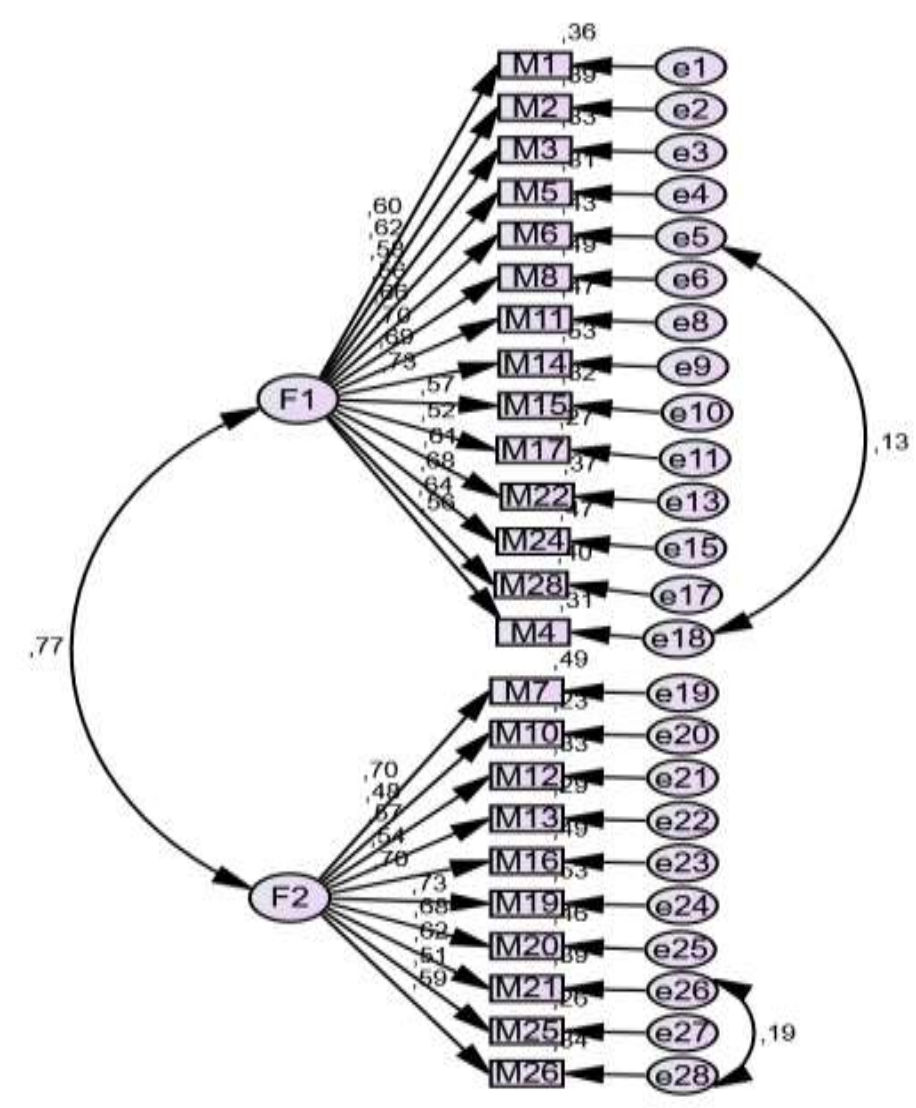


Fırat, N., \& Barut, Y. (2018). Sosyal Medya Bağımlllı̆̆ Ölçeği (SMBÖ)'nin geliştirilmesi: Geçerlik ve güvenirlik çalışması. Journal of Human Sciences, 15(4), 2266-2279. doi:10.14687/jhs.v15i4.5181

Modelin kabul edilebilir uyum sergilediğini doğrulamak için uyum indeksleri bazı kriterler göz önünü alınarak değerlendirilmiştir. İlk olarak iyi bir model uyumu için Ki-kare değerinin serbestlik derecesine oranı gerekli ve önemlidir. $\chi^{2} /$ sd oranının 3'ün altında olması mükemmel uyuma işaret etmektedir (Kline, 2005; Sümer, 2000).Yapılan DFA'da elde edilen bu değer $(\chi 2=469,858 ; \mathrm{sd}=249 ; \mathrm{x} 2 / \mathrm{sd}=1,89 ; \mathrm{p}=0.00)$ mükemmel uyumu göstermektedir. Bu kapsamda ölçme modelinin diğer genel uyum katsaylları GFI=.90; CFI=.93; TLI=.92; RMSEA=.052 ve $\mathrm{SRMR}=0,047$ olarak hesaplanmışır.

Hu ve Bentler (1999)'e göre SRMR'nin $\leq .08$ olması mükemmel uyumu ifade etmektedir. CFI değerinin .90'dan yüksek olması iyi uyumu, RMSEA'nin .08'den küçük olması kabul edilebilir uyumu göstermektedir (Çokluk, Şekercioğlu ve Büyüköztürk, 2010). Bu uyum indekslerine ilaveten hata varyansları $\mathrm{t}$ değeri incelenmiş ve istenen düzeyde olduğu belirlenmiştir. Ayrıca madde faktör yüklerinin .30 ve üzeri değerde olma koşulu aranmıştır. Şekil 2' de görüldüğü gibi, yoksunluk faktöründe madde faktör yüklerinin $(\lambda) .52-.73$ ile günlük yaşamı etkileme/kontrolsüzlük faktöründe madde faktör yüklerinin $(\lambda) .48-.73$ arasında değiștiği görülmüștür. $\mathrm{Bu}$ durumda elde edilen değerler ve maddelerin faktör yükleri modelin kabul edilebilir olduğunu göstermektedir. Ayrıca yapılan analiz sonucunda yoksunluk alt boyutunun 14 madde $(1,2,3,4,5,6,8,10,13,14,16,20,21,24)$; günlük yaşamı etkileme/kontrolsüzlük alt boyutunun ise 10 maddeden $(7,9,11,12,15,17,18,19,22,23)$ oluştuğu görülmektedir. Yapılan tüm analizler sonucunda 24 maddeli bir ölçek elde edilmiştir.

\section{Ölçüt Geçerliği}

Geçerlik çalısmaları kapsamında son olarak SMBÖ’nün ölçüt geçerliğini belirlemek amacıyla Bayraktar (2001) tarafindan uyarlanan İnternet Bağımlılı̆̆ı Ölçeği kullanılmıştır. Belirtilen ölçek 125 öğrenciye uygulanmış ve uygulama sonrasında ölçüt geçerliğini test etmek amacıyla iki ölçeğin alt boyutları ve toplamı arasındaki korelatif ilişkileri ortaya koymak amacıyla Pearson Momentler Çarpımı Korelasyon analizi yapılmıştır. Buna göre, SMBÖ'nün yoksunluk alt boyutu ile İÖ arasında pozitif ve anlamlı bir ilişki $(.675 ; \mathrm{p}<.000)$ olduğu, yine günlük yaşamı etkileme/kontrolsüzlük alt boyutu ile İBÖ arasında pozitif ve anlamlı bir ilişki (.768; p<.000) olduğu görülmüsstür. Bununla birlikte, son olarak SMBÖ toplam puanı ile İBÖ arasında pozitif ve anlamlı bir ilişki $(.781 ; \mathrm{p}<.000)$ olduğu görülmüştür. Yani katıllımcıların sosyal medya bağımlılıkları puanları arttıkça internet bağımlılıkları puanlanı da istatistiksel olarak anlamlı düzeyde artmaktadır. Elde edilen bu sonuçlar beklenen yöndedir ve SMBÖ'nün ölçüt geçerliliğine sahip olduğunu destekleyen niteliktedir.

\section{Test - Tekrar Test Uygulaması}

Son olarak tüm işlemlerin ardından test-tekrar test yöntemi ile bir güvenirlik katsayısı olarak devamlılık katsayısı hesaplanılmıştır. Bu amaçla 50 kişilik bir gruba ölçek formu üç hafta arayla iki kez uygulanmıştır. Üç hafta zaman aralığı ile ön test ve son testte alınan puanlar arasındaki kararlılı̆̆1 belirleyebilmek için Pearson momentler çarpım korelasyon katsayısına bakılmıştır (Karasar, 2007). Analiz sonuçları aşağıda sunulmuştur:

Tablo 7: Test-Tekrar Test Güvenirliğini Belirlemek İçin Yapılan Pearson Çarpım Moment Korelasyon Analiz Sonuçları

\begin{tabular}{lccc}
\hline & $\mathrm{N}$ & $\mathrm{r}$ & $p$ \\
\hline Yoksunluk & 50 & $.883^{*}$ & .000 \\
Günlük Yaşamı Etkileme/Kontrolsüzlük & 50 & $.846^{*}$ & .000 \\
Toplam & 50 & $.923^{*}$ & .000 \\
\hline
\end{tabular}

$*(p<0.01)$ 
Fırat, N., \& Barut, Y. (2018). Sosyal Medya Bağımlılı̆̆ı Ölçeği (SMBÖ)'nin geliştirilmesi: Geçerlik ve güvenirlik çalışması. Journal of Human Sciences, 15(4), 2266-2279. doi:10.14687/jhs.v15i4.5181

Test-tekrar test güvenirliğini belirlemek amacıyla yapılan Pearson çarpım moment korelasyon analizi sonucunda ölçeğin tamamı ve alt boyutları için elde edilen değerler arasındaki ilişki istatistiksel olarak pozitif yönde ve anlamlı bulunmuştur. Tabloda verilen değerlere bakıldığında ölçeğin farklı uygulamalarda tutarlı sonuçlar gösterdiğini dolayısıyla devamlılık katsayısı bağlamında güvenilir bulunduğunu ortaya koymaktadır.

\section{Sonuç, Tartışma ve Öneriler}

Günümüzde sosyal medya kullanımı artmakta ve hatta bir alışkanlık haline gelmiş bulunmaktadır. Cep telefonlarında internet özelliğinin yer almasıyla beraber sosyal medyaya ulaşım oldukça kolay hale gelmiş ve bu da sosyal medya bağımlilı̆ının artmasına sebep olmuştur. Türkiye'de sosyal medya bağımlllı̆̆ özellikle ergenler arasında her geçen gün artış gösteren bir durumdur. Bu duruma bağlı olarak ortaya çıkabilecek sorun alanlarının incelenmesi, önleyici ve iyileştirici programların geliştirilmesi büyük önem taşımaktadır. Bu çalışmada ortaokul ve lisede öğrenim gören ergenlerin sosyal medya bağımlılıklarını ölçmede kullanılabilecek "Sosyal Medya Bağımlılığı Ölçeği" geliştirmesi amaçlanmıştır.

Ölçek geliştirme çalışması sürecinde genel itibariyle şu işlemler gerçekleştirilmiştir. İlk olarak 35 kişilik öğrenci grubuna açık uçlu sorular yöneltilerek sosyal medya konusunda birer kompozisyon yazdırılmıştır. Hem yazdırılan bu kompozisyonlar ve hem de incelenen alanyazın dikkate alınarak 67 maddeden oluşan bir taslak form oluşturulmuştur. Uzman görüşleri ve yapılan pilot uygulamanın ardından form düzenlenerek analizlere geçilmiştir. SMBÖ'nün yap1 geçerliğini sınamak amacıyla açımlayıcı ve doğrulayıcı faktör analiz yöntemlerinden yararlanılmıştır. Ayrıca SMBÖ’nün ölçüt geçerliğini test etmek amacıyla İnternet Bağımlılığı Ölçeği (Bayraktar, 2001) ile aralarındaki korelasyon incelenmiştir. Ölçek güvenirliğini incelemek için ise SMBÖ'nün Cronbach Alpha katsayısı hesaplanmış ve test - tekrar test yöntemi kullanılmıştır.

Gerçekleştirilen açımlayıcı faktör analizi sonrası ölçeğin iki faktörlü yapıya sahip olduğu görülmüştür. Bu iki faktörün açıllanan toplam varyans miktarı \%51.405'tir. Sosyal alanlarda bu değerin \%40 ile \%60 arasında olması yeterli olarak kabul edilmektedir (Tavşancıl, 2010). Açıklanan toplam varyans oranı ölçeğin yapı geçerliğinin sağlandığının bir göstergesi olarak kabul edilebilir. Açımlayıc1 faktör analizi sonuçları incelendiğinde, her bir maddenin faktör yükünün yeterli faktör değerini taşıdığı ve alt boyutlarda toplanan maddelerin uygun bir şekilde kümelendiği görülmüsstür. Buna göre belirlenen alt boyutlar ilgili madde içerikleri, uzman görüşleri ve alanyazın da dikkate alınarak "Yoksunluk" ve "Günlük Yaşamı Etkileme/Kontrolsüzlük” olarak isimlendirilmiştir.

Ölçeğin güvenirlik çalışmaları kapsamında ise ilk olarak tespit edilen faktörler arası ilişkileri belirlemek amacıyla korelasyon analizi yapılmıştır. Analiz sonucunda ölçek faktörleri toplam puan arasında pozitif yönde anlamlı ilişki elde edilmesi ölçek faktörlerinin aynı yapı içinde olduklarını ortaya koymaktadır. Daha sonra ölçeğin alt boyutları ve toplamına dair iç tutarlık güvenirliği Cronbach Alfa katsayısı $(\alpha)$ ile hesaplanmıştır. Yapılan analiz sonucunda elde edilen değerler, ölçeğin iç tutarlılığının yüksek olduğunu ortaya koymaktadır.

Açımlayıcı faktör analizinin ardından ölçeğin ortaya çıkan bu yapısını test etmek amacıyla ise 335 öğrencide toplanan başka veriler üzerinden doğrulayıcı faktör analizi yapılmıştır. Analiz sonucunda Ki-kare/sd oranı 1.89 olarak bulunan bu çalışmada elde edilen değer, mükemmel uyuma işaret etmektedir. DFA sonucunda elde edilen diğer uyum indeksleri değerlendirilmiş ve indekslerin tümünün model uyumu için kabul edilebilir düzeyde oldukları belirlenmiştir (GFI=.90; CFI=.93; TLI=.92; RMSEA $=.052$ ve SRMR=0,047).

Açımlayıcı ve doğrulayıcı faktör analizleri sonrasında bakıldığında; SMBÖ’nün iki faktör ve toplam 24 maddeden oluştuğu görülmektedir. "Yoksunluk" alt boyutunda 14 madde ve "Günlük Yaşamı Etkileme/Kontrolsüzlük" alt boyutunda 10 madde bulunmaktadır. Ölçek beşli derecelendirmeli (Hiçbir Zaman=1, Nadiren=2, Bazen=3, S1k Sık=4 ve Her Zaman=5) olup, bireyler maddelerin karşısındaki derecelerden kendine uygun olanı seçerek cevaplamaktadırlar. Ayrıa ölçekte ters kodlanan madde bulunmamaktadır. SMBÖ'den alınabilecek toplam puan 24 ile 120; yoksunluk boyutu için alınabilecek toplam puan 14 ile 70, günlük yaşamı etkileme/kontrolsüzlük boyutu için ise 10 ile 50 arasında değişmektedir. Bireylerin SMBÖ'den elde ettikleri puan arttıkça, 
Fırat, N., \& Barut, Y. (2018). Sosyal Medya Bağımlılığı Ölçeği (SMBÖ)'nin geliştirilmesi: Geçerlik ve güvenirlik çalışması. Journal of Human Sciences, 15(4), 2266-2279. doi:10.14687/jhs.v15i4.5181

sosyal medya bağımlılıkları artmaktadır şeklinde yorumlanabilmektedir. Ayrıca ölçeğin ölçüt geçerliğine İnternet Bağımlılığ Ölçeği ile bakılmıştır ve bu iki ölçek arasında orta düzeyde bir ilişki değeri elde edilerek SMBÖ’nün ölçüt geçerliğine sahip olduğu kanıtlanmıştır. Sonuçlar benzer bir yapıyı ölçtüğü savunulan bu iki ölçüm aracı arasındaki benzerlik oranının iyi düzeyde olduğunu göstermektedir.

Buna ek olarak test-tekrar test güvenirliğini belirlemek amacıyla yapılan Pearson Çarpım Moment korelasyon analizi sonucunda ölçeğin tamamı ve alt boyutları için elde edilen değerler arasındaki pozitif ve anlamlı bir ilişki bulunması ölçeğin uygulamalarda tutarlı sonuçlar gösterdiğini, dolayısıyla devamlılık katsayısı bağlamında güvenilir bulunduğunu ortaya koymaktadır. Yapılan geçerlik ve güvenirlik işlemlerinin ardından ölçeğin, öğrencilerin sosyal medya bağımlılıklarını belirlemek amacıyla geçerli ve güvenilir biçimde kullanılabilecek bir ölçme aracı olduğunu ortaya koymaktadir.

Sosyal medya konusunda alanyazın incelendiğinde uluslararası çalısmalarda ergenlerin sosyal medya bağımlılığını belirlemeye yönelik kullanılabilecek ölçme aracının bulunduğu görülmektedir.Ancak Türkiye'deki alanyazın incelendiğinde sosyal medya bağımlilığı konusunda üniversite öğrencileri ve yetişkinlere (Tutgun-Ünal ve Deniz, 2015; Şahin ve Yağc1, 2017) yönelik ölçme araçlarının olduğu görülmüş fakat ergenlere yönelik ölçme aracına rastlanılmamıştır.Bu bağlamda, ergenlerin sosyal medya bağımlılı̆̆ını belirlenmesinde kullanılabilecek bir ölçme aracının geliştirildiği bu çalışmanın alanyazın için önemli olduğu düşünülmektedir.

Özellikle ergenler arasında sosyal medya kullanımı ve bağımlılı̆̆ının oldukça yaygın ve sürekli artan bir problem olduğu bilinmektedir.Bu nedenle ortaokul ve liselerde görev yapmakta olan okul psikolojik danışmanlarına, öğrencilerin sosyal medya bağımlılık düzeylerinin belirlenerek bağımlılı̆̆1 azaltmaya yönelik psikoeğitim programları hazırlanması ve uygulanması önerilebilir.Ayrıca bundan sonra yapılacak çalışmalarda demografik değişkenlere göre bireylerin sosyal medya bağımlılıklarının değişip değişmediğinin incelenmesi ülkemizde yapılacak çalışmalar için önemli veriler sağlayacaktır.Ayrıca sonraki çalışmalarda sosyal medya bağımlılığı ile akademik başarı, öz denetim, düşük özsaygı, yalnızlı gibi kavramlar arasındaki ilişkilerin araştırılmasının da önemli olduğu düşünülmektedir.

\section{Kaynakça}

Akyazı, E. ve Tutgun-Ünal, A. (2013).İletişim fakültesi öğrencilerinin amaç, benimseme, yalnızlık düzeyi ilişkisi bağlamında sosyal ağları kullanımı. Global Media Journal TR, 3(6), 1-24.

Al-Menayes, J. (2015). Psychometric properties and validation of the arabic social media addiction scale. Journal of Addiction, 1-6.

Argin, S. F. (2013). Ortaokul ve lise öğrencilerinin sosyal medyaya ilişkin tutumlarının incelenmesi (Çekmeköy örneği). (Yayımlanmamıs yüksek lisans tezi). Yeditepe Üniversitesi, Sosyal Bilimler Enstitüsü, İstanbul.

Bayraktar, F. (2001). İnternet kullanımının ergen gelişimindeki rolü (Yayımlanmamış yüksek lisans tezi). Ege Üniversitesi, Sosyal Bilimler Enstitüsü, İzmir.

Büyüköztürk, Ș. (2004).Veri analiæ̨i el kitabı. Ankara: Pegem A Yayıncilık.

Büyüköztürk, Ş. (2012). Sosyal bilimler için veri analiæi el kitabı (17.Baskı). Ankara: Pegem A Yayıncilık.

Byrne, B. M. (2010). Structural equation modeling with AMOS: Basic concepts, applications, and programming (2nd ed.). Madison, NY: Routledge.

Çokluk, Ö., Şekercioğlu, G. ve Büyüköztürk, Ş. (2010). Sosyal bilimler için çok değişkenli istatistik: SPSS ve LISREL uygulamalar. Pegem Akademi Yayınc1lik.

D'Souza, Q. (2006). Web 2.0 ideas for educators a guide to rss and more, version 2.0 http://www.teachinghacks.com/audio/100ideasWeb2educators.pdf Erişim Tarihi: 15.10.2015.

Fırat, N., \& Balcı Çelik, S. (2017). Cep telefonu bağımlllı̆̆ ölçeği (CBÖ)'nin 'Türkçe' ye uyarlanması: Geçerlik ve güvenirlik çalışması. Journal of Human Sciences, 14(3), 2875-2887. doi:10.14687/jhs.v14i3.1592 
Fırat, N., \& Barut, Y. (2018). Sosyal Medya Bağımlllı̆̆ Ölçeği (SMBÖ)'nin geliştirilmesi: Geçerlik ve güvenirlik çalışması. Journal of Human Sciences, 15(4), 2266-2279. doi:10.14687/jhs.v15i4.5181

Günlü, A. (2016). Ergenlerde internet ve problemli internet kullanım davranışının incelenmesi (Yüksek lisans tezi). Anadolu Üniversitesi, Eğitim Bilimleri Enstitüsü, Eskişehir.

Gürültü, E. (2016). Lise öğrencilerinin sosyal medya bağımlılıkları ve akademik erteleme davranışları arasındaki ilişkinin incelenmesi (Yüksek lisans tezi). Marmara Üniversitesi, Eğitim Bilimleri Enstitüsü, İstanbul.

Hu, L. T. ve Bentler, P. M. (1999). Cutoff criteria for fit indexes in covariance structure analysis: Conventional criteria versus new alternatives. Structural Equation Modeling: A Multidisciplinary Journal, 6(1), 1-55.

Karasar, N. (2007). Bilimsel araştırma yöntemi. (24. Basım). Ankara: Nobel Yayın Dağıtım.

Kenanoğlu, R. ve Kahyaoğlu, M. (2011). Okul öncesi öğrencilerin internet kullanımı ile bilişsel, duyuşsal ve sosyal davranışları arasındaki ilişki. 5th International Computer \& Instructional Technologies Symposium, 22-24 Eylül, Firat Üniversitesi, Elazı̆̆.

Kılıç, Ö. (2016). Ortaöğretim öğrencilerinin sosyal medyaya ilişkin tutumlarının incelenmesi (Yüksek lisans tezi). Cumhuriyet Üniversitesi, Eğitim Bilimleri Enstitüsü, Sivas.

Kline, R. B. (2005). Principles and practice of structural equation modeling. New York: The Guilford Press.

Köroğlu, O. \& Tutgun Ünal, A. (2013). Öğretmen adaylarının sosyal ağları benimseme düzeyleri ile yalnızlık düzeyleri arasındaki ilişki.Yeni Medya Kongresi, Kocaeli

Köseoğlu, Ö. (2012). Sosyal ağ sitesi kullanıcılarının motivasyonları: Facebook üzerine bir araştırma. Selcuk. Üniversitesi İletisim Fakültesi Dergisi, s.58-81.

Onat, F. (2010). Bir halkla ilişkiler uygulama alanı olarak sosyal medya kullanımı: sivil toplum örgütleri üzerine bir inceleme. Gą̊i Üniversitesi İletişim Fakültesi İletişim Kuram ve Araștırma Dergisi, 31, 103-122.

Otrar, M. ve Argin, F. S. (2015). Öğrencilerin sosyal medyaya ilişkin tutumlarini belirlemeye yönelik bir ölçek geliştirme çalışması. Ë̆̈tim ve Öğretim Araștrmalar Dergisi. 4(1), 2146-9199.

Seçer, İ. (2015). Psikolojik test gelistirme ve uyarlama süreci: spss ve lisrel uygulamalar. Ankara: An1

Sümer, N. (2000). Yapısal eşitlik modelleri: Temel kavramlar ve örnek uygulamalar. Türk Psikoloji Yazllar, 3(6), 49-74.

Şahin, C. (2011). An analysis of internet addiction levels of individuals according to various variables. The Turkish Online Journal of Educational Technology, 10 (4), 60-66.

Şahin, C. ve Yağc1, M. (2017). Sosyal Medya Bağımlılı̆̆1 Ölçeği- Yetişkin Formu: Geçerlilik ve güvenirlik çalışmas1. Abi Evran Üniversitesi Kerşehir Eğitim Fakültesi Dergisi (KEFAD). 18:1, 523-538.

Şar, A. H., Ayas, T. ve Horzum, M. B. (2015). Akıllı Telefon Bağımlllı̆̆ Ölçeği Geliştirme; Geçerlik ve güvenirlik çalışması. Online Journal Of Technology Addiction \& Cyberbullying, 2(1), 1-17.

Tavşancıl, E. (2010). Tutumlarn ölçülmesi ve spss ile veri analiæ̨i. Ankara: Nobel Yayınları

Tutgun-Ünal, A. (2015). Sosyal medya bağımlılı̆̆ı: Üniversite öğrencileri üzerine bir araştırma (Doktora tezi). Marmara Üniversitesi, Sosyal Bilimler Enstitüsü, İstanbul.

Tutkun Ünal, A. ve Deniz, L. (2015). Development of the social media addiction scale. Online Academic Journal of Information Technology, 6(21), 52-70. Doi: 10.5824/1309-1581.2015.4.004.x

TÜIK (2015). Hanehalk1 bilişim teknolojileri kullanım araştırması, http://www.tuik.gov.tr/PreHaberBultenleri.do?id=18660

Usluel, Y. K. \& Mazman, S. G. (2009).Sosyal ağların benimsenmesi ölçeği. Eğitim Bilimleri ve Uygulama, 8 (15), 139-160.

Vural, Z. B. \& Bat, M. (2010). Yeni bir iletişim ortamı olarak sosyal medya: Ege üniversitesi iletişim fakültesine yönelik bir araştırma. Journal of Yaşar University, 20 (5), 3348-3382.

Young, K. S. (1998). Internet addiction: The emergence of a new clinical disorder. CyberPsychology \& Behavior, 1(3), 237-244. 
Fırat, N., \& Barut, Y. (2018). Sosyal Medya Bağımlılı̆̆1 Ölçeği (SMBÖ)'nin geliştirilmesi: Geçerlik ve güvenirlik çalışması. Journal of Human Sciences, 15(4), 2266-2279. doi:10.14687/jhs.v15i4.5181

\section{Extended English Summary}

\section{Introduction}

Today, as well as the development rate of the communication tools, the diversity of such tools has also increased. While the content is only readable by the user in Web 1.0 technologies, that is, where the one-way communication is only possible, communication has begun to take place bidirectional with Web 2.0 technologies (D'Souza, 2006). Providing communication between humans, the Internet has enabled communication to gain a new dimension through the development of Web 2.0 tools. With the development of Web 2.0 technologies that aim at social communication, that is, mutual interaction, people are now searching for new internet environments (Argin, 2013). In this respect, a structure is established in which the communication of users is also included (Köseoğlu, 2012). These developments have led to the creation of new platforms in the name of social media and caused the individuals who use the internet to spend more time with social media.

The use of social media as such, and even becoming a habit as part of everyday life, has caused researchers to bring up the over-use of social media into their agendas (Tutgun-Unal, 2015). Therefore, social media dependence has also been of interest to researchers. The diversity of pages with social content attracts every segment the society from children to adults. Particularly during adolescence, individuals are unconsciously directly receiving the material presented without choosing and being affected in the same way (Gürültü, 2016). Current researches show that especially young people use social media more (Akyazı and Tutgun-Ünal, 2013; Köroğlu and Tutgun-Ünal, 2013; Usluel and Mazman, 2009; Vural and Bat, 2010).Therefore, it has become more of an issue to examine and monitor the problem areas that may arise due to the widespread use of social media in particular and of internet in general among teenagers in Turkey every passing day. When the domestic literature is examined, it is seen that studies on internet addiction are mostly carried out and studies on social media dependency are conducted with adults and university students. Thus, in this study, it was aimed to develop and to present to literature a "Social Media Addiction Scale" which can be used to measure social media addictions of adolescents who are studying in high schools and secondary schools.

\section{Method}

The research is a scale development study. Because of this, the research includes Social Media Addiction Scale (SMAS) development procedures. These processes were carried out in four stages as determining scale items, referring to expert opinion, applying scale, and determining reliability and validity.

\section{Study Group}

The participants of the study consists of 830 students who are studying in different secondary schools (7th and 8th grade) and high schools in Amasya. In addition, two pilot schemes were implemented with a total of 142 students, including 70 in the first and the scale was formed. Of the students participated in the survey $46.3 \%$ were girls and $53.7 \%$ of the students were boys.

\section{Findings}

\section{Findings for Validity and Reliability}

In the scale development study, firstly open-ended questions were asked to the group of 35 students and they were asked to write a composition about social media. A draft form consisting of 67 items was created, taking into account both these compositions and the analyzed literature. Following expert opinions and two pilot implementations, the form was organised and analyses were started.

Explanatory and confirmatory factor analysis methods were used to test the construct validity of the SMAS. After the exploratory factor analysis performed, it was seen that the scale had 
Fırat, N., \& Barut, Y. (2018). Sosyal Medya Bağımlılığı Ölçeği (SMBÖ)'nin geliştirilmesi: Geçerlik ve güvenirlik çalışması. Journal of Human Sciences, 15(4), 2266-2279. doi:10.14687/jhs.v15i4.5181

a two factor-structure. The total variance amount explained by these two factors is $51,405 \%$. This value is expected to be between $40 \%$ and $60 \%$ in social areas (Tavşancil, 2010). Taking into consideration the content of the relevant articles, expert opinions and literature, the sub-dimensions determined as the result of the analysis were named as "Deprivation" and "Influence on Daily Life/Uncontrollability".

Pearson Product-Moment Correlation analysis conducted to determine whether there was a significant relationship between the factors determined on the scale showed that there was a significant positive correlation between the factors. It was identified that there is a significant relationship between the Deprivation subscale and the Influence on Daily Life / Uncontrollability subscale $(\mathrm{r}=.677 ; \mathrm{p}<.001)$ in the positive direction. These values show that the factors are within the same structure. The reliability of the internal consistency of the subscales and the sum of the scale were calculated by the Cronbach Alpha coefficient $(\alpha)$. As a result of the analysis made, Cronbach Alpha values were obtained as .90 for the deprivation subscale, .86 for the subscale for influence on daily life / uncontrollability subscale, and finally as .93 for the sum of the scale. These values show that the internal consistency of the scale is high.

Confirmatory factor analysis (CFA) was performed on other data collected from 335 students in order to test this structure of the scale, which emerged after the exploratory factor analysis. The value obtained in this study, where the Chi-square/sd ratio is 1.89 as a result of the analysis, indicates perfect fit. Other fit indices obtained as a result of CFA were evaluated and all of the indices were found to be acceptable for model fitting (GFI=.90; CFI=.93; TLI=.92; RMSEA=.052 and SRMR=0.047). As a result of the analysis, it was determined that the scale structure was confirmed. In addition, the correlation between the scale and the Internet Addiction Scale (Bayraktar, 2001) was examined to test the criterion validity of the scale. It has been proved that SMAS has a criterion of validity by obtaining a meaningful correlation value between the two scales in positive direction.

Finally, test-retest method and coefficient of persistence as a reliability coefficient were calculated after all operations. For this purpose, the scale form was applied to a group of 50 people twice in three weeks. In order to determine the stability between the three-week time interval and the scores obtained in the pre-test and post-test, the Pearson moment-product correlation coefficient was examined and statistically positive and significant correlations were found for the whole of the scale and its sub-dimensions. These results show that the scale shows consistent results in different applications.

\section{Discussion and Conclusion}

When the literature is investigated, it can seen that there are measurement tools that can be used to determine social media addiction of adolescents in international studies. However, when the literature in Turkey is investigated, it can be observed that there are measurement tools for college students and adults about social media addiction (Tutgun-Ünal and Deniz, 2015; Şahin and Yağc1, 2017), but no such tool couldn't be detected for adolescents. In this context, it is thought that this study, in which a measurement tool that can be used to determine social media addiction of adolescents is important for the literature.

Searching the literature on social media showed that there are very few studies on adolescents. Social media use and addiction among adolescents is known to be a very common and ever increasing problem. For this reason, school psychological counsellors working in secondary schools and high schools may be advised to prepare and implement psychoeducational programs to reduce social media addiction of the students by determining their addiction levels. In addition, fexamining in future studies whether social media addictions of individuals have changed according to demographic variables will provide important data for studies to be carried out in our country. It is also thought that it is important to investigate the relationship between social media addiction and concepts such as academic achievement, self-control, low self-esteem and loneliness in subsequent studies. 